\title{
Acquired heterotopic ossification in hips and knees following encephalitis: case report and literature review
}

\author{
Xianghong Zhang, Shuo Jie, Tang Liu* and Xiangsheng Zhang
}

\begin{abstract}
Background: Heterotopic ossification $(\mathrm{HO})$ is a rare and potentially detrimental complication of soft-tissue trauma, amputations, central nervous system injury (traumatic brain injuries, spinal cord lesions, tumors, encephalitis), vasculopathies, arthroplasties and burn injury, characterized by lamellar bone growth in non-osseous tissues such as the muscle and the joint capsule. Heterotopic ossification associated with encephalitis is rare and the occurrence of excessive, symptomatic heterotopic ossification around bilateral hips and bilateral knees is rarely described in the literature.

Case presentation: We present a 47-year-old man with heterotopic ossification in the bilateral hips and bilateral knees that prevented him from walking after being attacked by encephalitis as the case study. He developed severe pain and significantly impaired range of motion of bilateral hips and bilateral knees. Research so far revealed that the management of heterotopic ossification is controversial. After requiring revision surgery resection of heterotopic ossification, reconstruction of the medial collateral ligament and adjunctive pharmacotherapy of $200 \mathrm{mg}$ Celecoxib for 8 weeks after operation, he regained mobility of his joints. On review of X-ray, there was no recurrence of $\mathrm{HO}$ and no loosening of rivets which were used in the reconstruction of medial collateral ligament.

Conclusion: Heterotopic ossification in the bilateral hip joints and bilateral knee joints associated with encephalitis have never been reported previously. Daily functions of heterotopic ossification patients can be hampered by pain, inflammation, reduced mobility, the loss of normal posture and other complications. Further studies of presumptive root causes, the early diagnosis, preventability and optimal therapeutic measures for heterotopic ossification following encephalitis are required. Different patient should be managed with different appropriated protocol based on the risk of individual patient and the institutional experience.
\end{abstract}

Keywords: Heterotopic ossification, Encephalitis, Hip, Knee

\section{Background}

Heterotopic ossification $(\mathrm{HO})$ is a pathological process of lamellar bone formation in soft tissue outside of skeleton. HO occurs frequently after severe head injury, spinal injury, non-traumatic intracranial lesion and longterm coma [1,2]. However, the occurrence of excessive, symptomatic heterotopic ossification around bilateral hips and bilateral knees is rarely described in the literature. Daily functions of HO patients can be hampered by the loss of normal posture, pain, inflammation, reduced

\footnotetext{
*Correspondence: liutang1981@126.com

Department of Orthopedics, the Second Xiangya Hospital, Central South University, 139 Renmin Road, Changsha, Hunan 410011, P.R. China
}

mobility, formation of pressure ulcers, deep venous thrombosis and other complications [3]. Also there is a limited number of cases in the medical literature where the condition affects one or two anatomical regions in association with encephalitis. The etiopathogenesis of $\mathrm{HO}$ is unknown and there is lack of consensus on treatment modalities [4].

\section{Case presentation}

A 47-year-old man, with no past medical history, suddenly complained of headaches, without fever, vomiting and altered consciousness on February 10, 2012. He was admitted to a nearby clinic, but it was useless and the headache got aggravated, following hyperpyrexia. To strive for better 
treatment, he got admitted into the neurology department of a superior hospital. After admission, there were apparent cognitive deficits, namely: disorientation, short attention span, and gradual disordered consciousness which progressed into coma. A magnetic resonance imaging (MRI) of the brain was unremarkable. Examination of cerebrospinal fluid and cerebrospinal fluid cultures were negative, so he was then treated for presumed viral encephalitis. According to the profile, results of blood test and imaging evidence, the patient was treated with antiviral therapy, antiepileptic therapy and empirical antibiotics within 30 days period of coma. After this period of 30 days under coma, his mental state and speech improved with vigorous and effective treatment, but the ambulation did not improve significantly. Therefore, he had difficulty using his lower extremities.

From then on, he consulted with several doctors from time to time regarding the stiffness of both the hips and knees, but the condition of his lower extremities did not improve. Ten months after the onset of the coma, he came to our department of orthopedics in order to pursue natural movement. Both hips and knees were stiff and the clinical evaluation revealed the following passive ranges of motion of hips and knees as showed in the Table 1 below. All other joints were normal.

The patient's laboratory findings were normal except for a slight increase in erythrocyte sedimentation rate (ESR) (24 mm/h; normal, 0-15 mm/h). Radiographs of the pelvis showed para-articular $\mathrm{HO}$ on the interior aspect of both femoral necks (Figure 1). Anterioposterior and lateral radiographs of knees (Figure 2) showed HO on the peripheral areas of knee-joints, especially on the medial. Lesions of four joints were also clearly showed in radiographs of both lower extremities (Figure 3).

After admission to our institution, the patient and his family received pre-operation counseling, including the explanations of the available management options, expected outcome and possible complications. After extensive discussion of the risks and benefits of revision surgical excision of $\mathrm{HO}$ resection and concomitant peri-operative pharmacotherapy of Celecoxib for decreasing the risk of $\mathrm{HO}$ recurrence, the patient and his family agreed to proceed with the procedure as discussed. On December 5, 2012, he underwent the first operation: Revision surgical

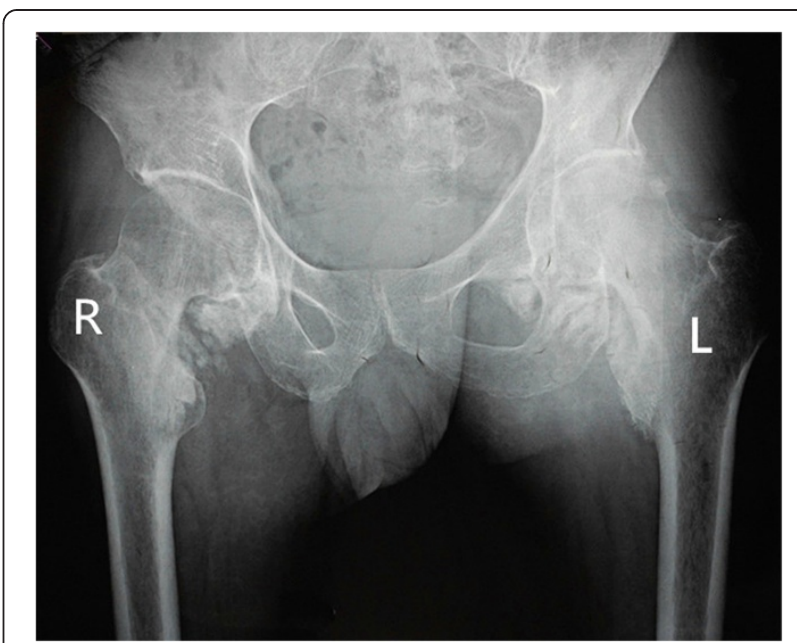

Figure 1 Preoperative radiographs of the pelvis shows para-articular $\mathrm{HO}$ on the interior aspect of both the femoral necks.

excision of the heterotopic bone of both knees was performed. In the surgery, an osteotome was used to excise the ossific mass in sufficient amount to free the joints and the medial collateral ligaments of both knees had degeneratively changed. Therefore, the reconstruction of the medial collateral ligament was applied. One month later, he underwent another revision surgery of excision of the heterotopic bone of both hips. The patient tolerated the surgical procedures well. After operation, the patient was given $200 \mathrm{mg}$ Celecoxib orally once a day for a total of 8 weeks postoperatively. Postoperative radiographs of both knees showed that most of heterotopic bone of both knees had been excised (Figures 4 and 5). At the last follow-up visit, 18 months after the operation (is 28 months after the coma), he had no pain and could walk independently. The passive ranges of motion of hips and knees had significantly improved and the detailed information can be seen in above chart (Table 1). On review of X-ray, there was no recurrence of $\mathrm{HO}$ and no loosening of rivets used in the reconstruction of medial collateral ligament (Figures 6 and 7).

\section{Discussion}

$\mathrm{HO}$ is a rare and potentially detrimental complication of soft-tissue trauma, amputations, central nervous system

Table 1 The comparison of range of motion between pre-operation and post-operation

\begin{tabular}{|c|c|c|c|c|c|c|}
\hline & \multicolumn{3}{|l|}{ Flexion } & \multicolumn{3}{|l|}{ Extension } \\
\hline & Pre-operation & $\begin{array}{l}13 \text { months after } \\
\text { the operation }\end{array}$ & $\begin{array}{l}18 \text { months after } \\
\text { the operation }\end{array}$ & Pre-operation & $\begin{array}{l}13 \text { months after } \\
\text { the operation }\end{array}$ & $\begin{array}{l}18 \text { months after } \\
\text { the operation }\end{array}$ \\
\hline Left hip & $0^{\circ}-25^{\circ}$ & $0^{\circ}-85^{\circ}$ & $0^{\circ}-110^{\circ}$ & Flexion deformity & $0^{\circ}-15^{\circ}$ & $0^{\circ}-15^{\circ}$ \\
\hline Right hip & $0^{\circ}-15^{\circ}$ & $0^{\circ}-80^{\circ}$ & $0^{\circ}-105^{\circ}$ & & $0^{\circ}-10^{\circ}$ & $0^{\circ}-10^{\circ}$ \\
\hline Left knee & $0^{\circ}-15^{\circ}$ & $0^{\circ}-100^{\circ}$ & $0^{\circ}-125^{\circ}$ & & $0^{\circ}$ & $0^{\circ}$ \\
\hline Right knee & $0^{\circ}-10^{\circ}$ & $0^{\circ}-90^{\circ}$ & $0^{\circ}-127^{\circ}$ & & $0^{\circ}$ & $0^{\circ}$ \\
\hline
\end{tabular}




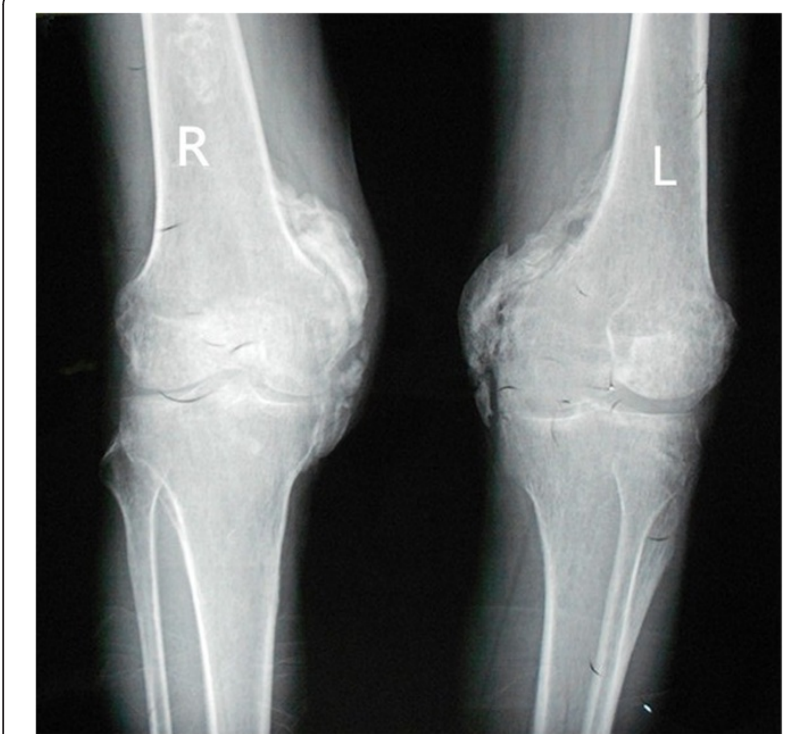

Figure 2 Preoperative radiographs of anterioposterior and lateral radiographs of knees shows $\mathrm{HO}$ on the peripheral areas of knee-joints, especially on the interior.

injury (traumatic brain injuries, spinal cord lesions, tumors, encephalitis) [5,6], vasculopathies, arthroplasties and burn injury, characterized by lamellar bone growth in non-osseous tissues such as the muscle and the joint capsule. After brain or spinal cord injury, trauma, neurologic disease or injuries, or hereditary disease, HO may occur [4]. HO associated with viral encephalitis is very rare [7]. The occurrence of excessive, symptomatic heterotopic ossification around bilateral hips and bilateral knees is rarely described in the literature. Our report demonstrates heterotopic bone arising from periarticular region of both hips and both knees in a patient who suffered one month prolonged coma following encephalitis. To the best of our knowledge, this is the first report of $\mathrm{HO}$ in both hips and both knees following encephalitis. Under reviewing literature, we made a simple chart (Table 2) below to show distinctions between patients who suffered multiple-joint following encephalitis. Daily functions of heterotopic ossification patients can be hampered by pain, inflammation, reduced mobility, the loss of normal posture and other complications [3]. Research so far reveal that the management of $\mathrm{HO}$ is controversial. As supported by the successful outcome in the present study, we recommend considering $\mathrm{HO}$ resection in conjunction with peri-operative pharmacotherapy of Celecoxib. In our current case study, the patient suffered stiffness of hips and knees and his family received pre-operation counseling, of which on December 5, 2012 he underwent the first operations. In order to free the both knee joints, We removed sufficient ossific mass and reconstructed the medial collateral ligament, This is the significant difference to

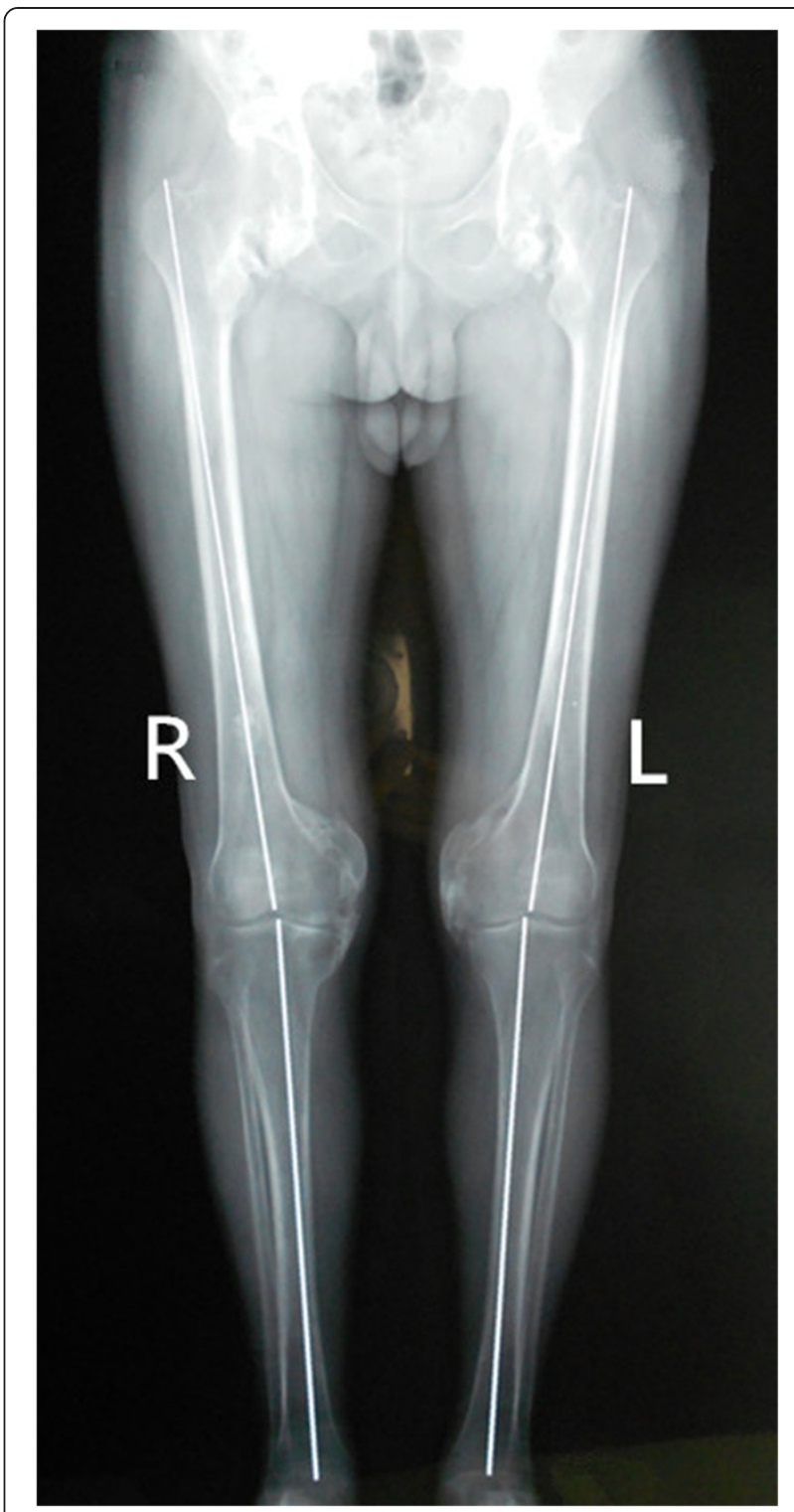

Figure 3 Preoperative radiographs of both lower extremities shows Lesions of four joints.

other reported cases in literature which can also make the joint more stable. One month later, he underwent another revision surgical resection of the heterotopic bone of both hips. The patient tolerated the surgical procedure well. After operation, the patient was given medical treatment of $200 \mathrm{mg}$ Celecoxib orally once a day for a total of 8 weeks. He had no recurrence of $\mathrm{HO}$ and no loose rivets for 18 months after the surgery with a significantly improved ranges of motion of hips and knees described in detail above.

The mechanism and pathophysiology which can lead to $\mathrm{HO}$ formation is still not fully understood. And molecular mechanisms of $\mathrm{HO}$ have not been fully elucidated. Many studies showed that primitive mesenchymal 


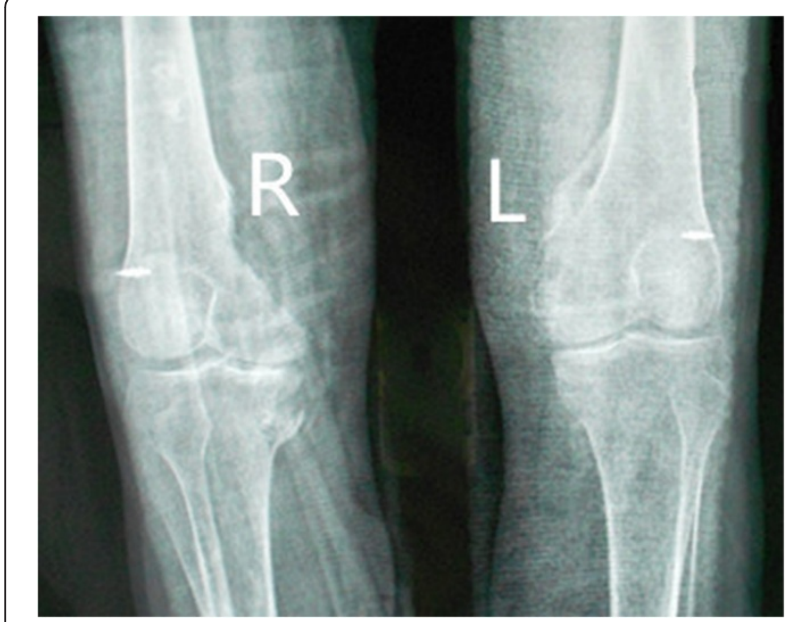

Figure 4 Postoperative radiographs of anterioposterior radiographs of knees shows no loosening of rivets and no recurrence 13 moths after the excision of the ossific mass.

cells differentiate into osteoblasts which would lead to $\mathrm{HO}$ formation and the origin of these mesenchymal cells and the stimulus are poorly understood [8]. Gannon FH et al. discovered that inflammation first occurs in response to stimulations, including surgery, trauma and viral illnesses [9]. Inflammatory and skeletogenic signaling pathways are also supposed to play critical roles in $\mathrm{HO}$ formation. Bidner SM et al. [10] proposed that failure of control in the immune system, central nervous system or indigenous inflammatory response lead to the release of inducing agents, resulting in HO formation. Urist [11] et al. discovered that demineralized bone matrix can induce the formation of HO. They also presented bone morphogenetic protein as the true inductor. Ho SSW [12] et al., recently put forward that Prostaglandin E2 is a transmitter to promote the original cell differentiation. Chalmers J [13] et al. proposed that the following

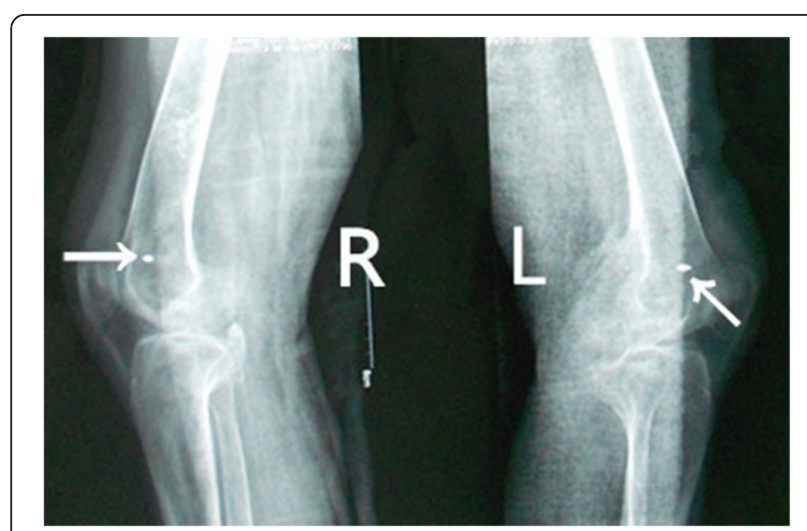

Figure 5 Postoperative radiographs of lateral radiographs of knees shows no loosening of rivets and no recurrence 13 moths after the excision of the ossific mass.

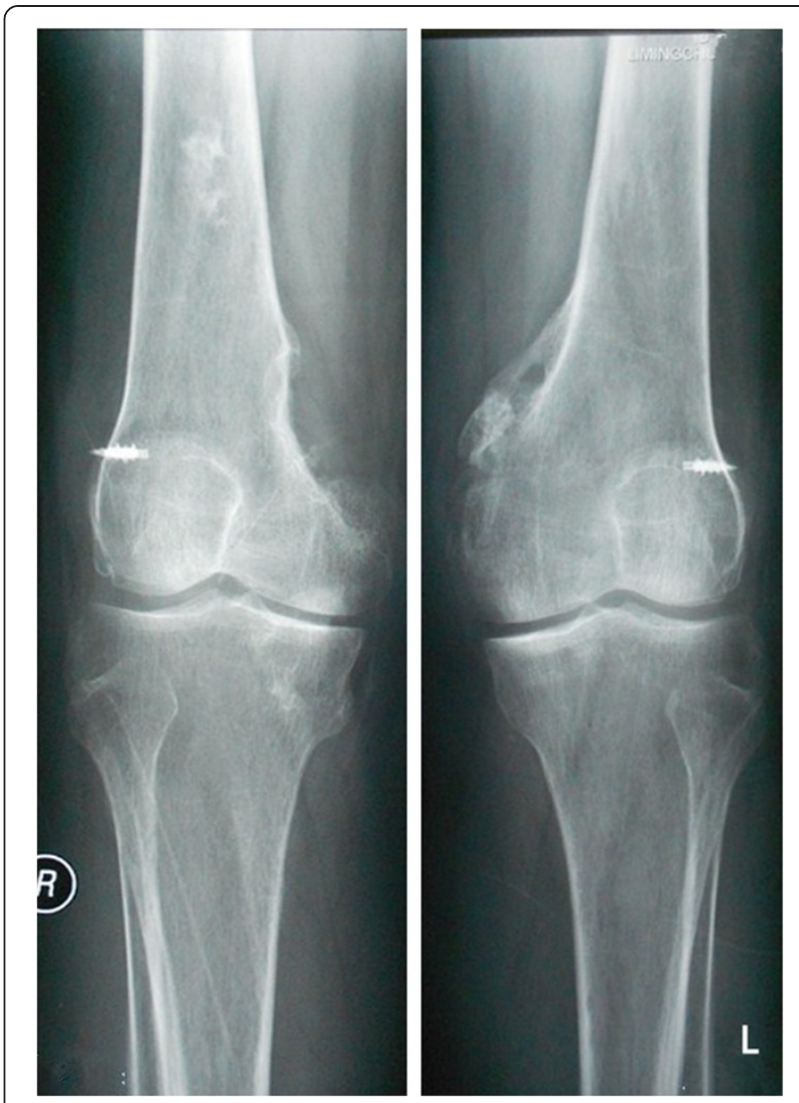

Figure 6 Postoperative radiographs of knees shows no loosening of rivets and no recurrence 18 moths after the excision of the ossific mass.

three requirements are necessary for $\mathrm{HO}$ formation, namely: inducing agent, osteogenic precursor cell and an environment which is permissive to osteogenesis. Once these conditions are meet, mesencnchymal cells are recruited, which then proliferate and differentiate into chondrocytes and/or osteoblasts, and ultimately lead to ectopic bone
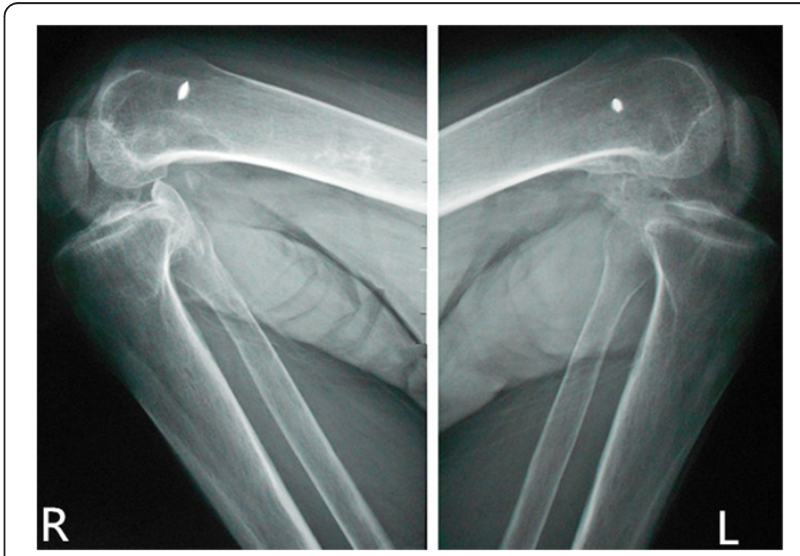

Figure 7 Postoperative radiographs of knees shows the passive range of motion of knees had significantly improved. 
Table 2 A brief summary about patients associated with HO following encephalitis

\begin{tabular}{|c|c|c|c|c|c|c|}
\hline Authors & Age/gender & Time of coma & The affected joints & Locations & Therapies & Consequence \\
\hline Tay [18] et al. & 26/female & 28 days & Bilateral hips & $\begin{array}{l}\text { Image of CT showed: medial aspect } \\
\text { of upper thighs }\end{array}$ & Surgery and radiotherapy & $\begin{array}{l}\text { No recurrence and moderate } \\
\text { gain in the rage of motion }\end{array}$ \\
\hline \multirow[t]{2}{*}{ Jayasundara [8] et al. } & $21 /$ male & 35 days & $\begin{array}{l}\text { Bilateral hips and } \\
\text { right elbow }\end{array}$ & $\begin{array}{l}\subset T \text { showed: anterior,posterior and } \\
\text { lateral aspects of both hips, }\end{array}$ & Surgery and physiotherapy & $\begin{array}{l}\text { No recurrence and have acceptable range } \\
\text { of movements at the affected joints }\end{array}$ \\
\hline & & & & $\begin{array}{l}\text { Radiograph of the pelvis showed: } \\
\text { anteroposterior }\end{array}$ & & \\
\hline Saito [30] et al. & 26/female & 40 days & Bilateral knees & $\begin{array}{l}C T \text { showed: Large area of the left distal } \\
\text { femur and small area of right knee }\end{array}$ & $\begin{array}{l}\text { Surgery and } 800 \mathrm{mg} \text { daily } \\
\text { of etidronate disodium }\end{array}$ & $\begin{array}{l}\text { Slight recurrence occurred } 3 \text { weeks } \\
\text { after surgery }\end{array}$ \\
\hline An [7] et al. & 38/female & 13 months & $\begin{array}{l}\text { Right shoulder and } \\
\text { left elbow }\end{array}$ & Unknown & $\begin{array}{l}\text { Excision,physical and } \\
\text { diphosphonate postoperation }\end{array}$ & $\begin{array}{l}\text { No recurrence and the range of motion } \\
\text { improved markedly }\end{array}$ \\
\hline Ours case & 47/male & 1 month & Both hips and knees & $\begin{array}{l}\text { interior aspect of both the femoral } \\
\text { necks and the peripheral areas of } \\
\text { knee-joints, especially interior }\end{array}$ & $\begin{array}{l}\text { Excision and } 200 \text { mg daily } \\
\text { of Celecoxib }\end{array}$ & No recurrence and walk independently \\
\hline
\end{tabular}


formation [3]. Botolin et al. [14], also put forward that both the reaming debris and the extent of traumatic intraoperative injury to the surrounding soft tissues at the operative site play important roles in the development of $\mathrm{HO}$ after antegrade reamed femoral IMM in their case study. Several studies also have demonstrated that the low-oxygen tension [15] and neurotransmitters are involved in the process of $\mathrm{HO}$ formation. Glrland DE et al. [16] told us that prolonged coma, mechanical ventilation, spasticity and limited extremity movements may be the initiators of neurogenic HO. Although the pathogenic mechanism of $\mathrm{HO}$ remains unclear, functional immobility has been reported to be a risk factor [17]. Therefore, it is obvious that further studies for the mechanism and pathophysiology of $\mathrm{HO}$ are required.

It is also difficult to ascertain when the $\mathrm{HO}$ formation begins accurately, because the subject of $\mathrm{HO}$ formation has no specificity [18] and lacks a reliable method for early diagnosis. Atypical early clinical performance of $\mathrm{HO}$ are the causes of hard distinction from cellulitis, osteomyelitis, thrombophlebitis and tumor. Without early detection or intervention, progression of $\mathrm{HO}$ can lead to severe longterm effects, including restricted joint mobility, severe pain and nerve entrapment. In the aspect of biochemical markers, alkaline phosphatase (ALP) has some certain clinical significance of early diagnosis of HO [19], but ALP has no specificity. Therefore, it is difficult to determine the onset of $\mathrm{HO}$, including $\mathrm{HO}$ following encephalitis in using biochemical markers. $\mathrm{HO}$ at different stages shows different imaging characteristics. Someone thought magnetic resonance imaging (MRI) is the best effective method for the diagnosis of early ectopic ossification, whiles X-ray and computed tomography (CT) can be used for review. Practice literature reports tell us that X-ray can not discover HO until 4-6 weeks later [20]. While some literature show that the most sensitive imaging modality for early detection of $\mathrm{HO}$ is three-phase bone scintigraphy which can also monitor the metabolic activity and degree of maturity of HO [19,21]. Although radiographic techniques such as computed tomography and magnetic resonance image provide high detailed anatomic representation of late stage $\mathrm{HO}$, these modalities cannot detect early stages of HO. In summary, current imaging modalities, including CT, MRI and three-phase bone scintigraphy through helpful in late diagnosis are inadequate to help clinicians detect early $\mathrm{HO}$ development. The formation of $\mathrm{HO}$ begins within days to weeks of the inciting event. The disease has already spread beyond the point where it can be treated and impeded with oral medications, once visible through these current techniques. That is to say, none of the available prophylactic measures would affect the outcome of $\mathrm{HO}$ once the process begun [22]. Therefore, a urgent need exists to improve the current diagnostic modalities for $\mathrm{HO}$ which are inadequate to diagnose and intervene on $\mathrm{HO}$ at early time-points. Many researches showed that Roman Probe propelled non-invasive, transcutaneous evaluation of heterotopic bone formation. Petrson JR [23] et al. also suggested that Roman Spectroscopy allowed for detection of $\mathrm{HO}$ formation as early as 5 days in mice following a burn injury. Hence, we should try hard to develop novel screening techniques to visualize and detect the onset and progression of $\mathrm{HO}$ with high sensitivity and specificity.

Numerous treatment options, including pharmacotherapy (such as: non-steroidal Anti-inflammatory drugs (NSAIDs) [24], disodium etidronate (EHDP) et al.), motortherapy, radiotherapy, surgical therapy et al., are available but decision on which modality to choose depends on a detailed and accurate assessment of the disease process. NSAIDs were recognized as the most effective drugs to prevent the formation of $\mathrm{HO}$ after operation of acetabulum fracture [25]. Most doctors agree that indomethacin is the best choice among NSAIDs not only prevent $\mathrm{HO}$ but also slows down the process of $\mathrm{HO}$ development. However, the application of NSAIDs is relatively limited, for its adverse drug reaction such as gastrointestinal ulceration, decreased platelet aggregation and renal toxicity. Coventry $\mathrm{MB}$ [26] et al. conducted a research with patients who had $\mathrm{HO}$ following total hip arthroplasty, and they believed that radiation aids to prevent the formation of ectopic bone. However, the potential side effect that we should consider is carcinogenesis. Despite the risk that it can trigger another round of $\mathrm{HO}$, surgery remains the only treatment option to date once bone tissue has formed. To increase the range of movements of the joints and improve function and quality of life, surgery was a good choice among treatments. Therefore, we choose the method of revision surgical resection in our case study.

However, it is difficulty to decide when the best time is for the revision surgical resection of HO? Many researches have indicated that there is a need to wait for the heterotopic bone to matured before the procedure is undertaken. Garland et al. suggested that it requires 18month before surgical excision in order to allow the bone to mature [27]. And most scholars recommended a minimum wait of 1 year after ectopic bone formation ahead of surgical excision [28]. Garland DE recommended that $\mathrm{HO}$ resection should be performed at different time intervals according to the $\mathrm{HO}$ aetiology: traumatic $\mathrm{HO}$ should be resected at 6-9 months, spinal cord injury at 1 years and traumatic brain injury $\mathrm{HO}$ at 1.5 years [29]. Serum alkaline phosphatase (ALP) is an important factor we should use to determine the timing of $\mathrm{HO}$ resection. Though the maturity of heterotopic bone is difficult to evaluate, it is also important to prevent the high recurrence rate relevant to excision of immature ectopic bone [30]. Recurrence is also an important complication of $\mathrm{HO}$ which should be considered after excision. The risk of 
recurrence is higher in patients undergoing multiple operations sequentially [31] and it is found out that the risk of recurrence $\mathrm{HO}$ was high if the three or more joints were involved [27]. Botolin et al. supposed that diligent intraoperative care of the soft tissues and copious fluid irrigation with saline in the procedure of revision surgery appear to decrease the recurrence rate [14]. In order to free the stiffness in joint because of $\mathrm{HO}$, it is necessary to remove sufficient ossific mass but complete excision is not necessary. And to decrease the recurrence rate of $\mathrm{HO}$, active exercises should begin after the first postoperative week [27].

In summary, as major treatment options discussed above have negative side effects to some extent, it is important to evaluate the risk of individual patients, and provide safe and effective treatments for them. Further studies for the mechanism and pathophysiology, the early diagnosis and optimal managements of HO following encephalitis are required.

\section{Conclusion}

Heterotopic ossification in the bilateral hip joints and bilateral knee joints associated with encephalitis have never been reported previously. Daily functions of heterotopic ossification patients can be hampered by pain, inflammation, reduced mobility, the loss of normal posture, and other complications. Therefore, to fully understand the pathogenesis of $\mathrm{HO}$ and to determine its risk factors, root causes and preventability of this potentially detrimental complications, further study is required. Different patient should be managed with a different appropriated protocol based on the risk of individual patient and the institutional experience.

\section{Consent}

Written informed consent was obtained from the patient for publication of this Case report and any accompanying images. A copy of the written consent is available for review by the Editor of this journal.

\section{Competing interests}

The authors declare that they have no competing interests.

\begin{abstract}
Authors' contributions
$\mathrm{XZ}$ accountable for the execution of the case report, the integrity and analysis of the data and the writing of the manuscript. SJ accountable for the analysis of the data and the writing of the manuscript. TL accountable for the conception and execution of the case report. XZ accountable for the conception and execution of the case report. All authors read and approved the final manuscript.
\end{abstract}

Authors' information

Xianghong Zhang and Shuo Jie are co-first authors.

\section{Acknowledgements}

The authors would like to thank the participating patients, as well as the study nurses, co-investigators, and colleagues who made this case report possible.
Received: 27 January 2014 Accepted: 30 September 2014

Published: 3 October 2014

\section{References}

1. Pape HC, Marsh S, Morley JR, Krettek C, Giannoudis PV: Current concepts in the development of heterotopic ossification. J Bone Joint Surg (Br) 2004, 86:783-787.

2. Kluger $\mathrm{G}$, Kochs A, Holthausen H: Heterotopic ossification in childhood and adolescence. J Child Neurol 2000, 15:406-413.

3. Shimono K, Uchibe K, Kuboki T, Iwamoto M: The pathophysiology of heterotopic ossification: Current treatment considerations in dentistry. Jpn Dent Sci Rev 2014, 50:1-8.

4. Vanden Bossche L, Vanderstraeten G: Heterotopic ossification: a review. J Rehabil Med 2005, 37:129-136.

5. Sakellariou VI, Grigoriou E, Mavrogenis AF, Soucacos PN, Papagelopoulos PJ: Heterotopic ossification following traumatic brain injury and spinal cord injury: insight into the etiology and pathophysiology. J Musculoskelet Neuronal Interact 2012, 12(4):230-240.

6. Seipel R, Langner S, Platz T, Lippa M, Kuehn JP, Hosten N: Neurogenic heterotopic ossification: epidemiology and morphology on conventional radiographs in an early neurological rehabilitation population. Skeletal Radiol 2012, 41(1):61-66.

7. An HS, Ebraheim N, Kim K, Jackson WT, Kane JT: Heterotopic ossification and pseudosrthrosis in the shoulder following encephalitis: a case reprt and review of the literature. Clin Orthop Relat Res 1987, 219:291-298.

8. Jayasundara JA, Punchihewa GL, de Alwis DS, Rwnuka MD: Short-term outcome after resection of neurogenic heterotopic ossification around the hips and elbow following encephalitis. Singapore Med J 2012, 53:97-100.

9. Gannon FH, Valentine BA, Shore EM, Zasloff MA, Kaplan FS: Acute lymphocytic infiltration in an extremely early lesion of fibrodysplasia ossificans progressiva. Clin Orthop Rel Res 1998, 346:19-25.

10. Bidner SM, Rubins IM, Desjardins JV, Zukor DJ, Goltzman D: Evidence for a humoral mechanism for enhanced osteogenesis after head injury. J Bone Joint Surg Am 1990, 72:1144-1149.

11. Urist MR, Nakagewa M, Nakata N, Nogami H: Experimental myositis ossification: cartilage and bone formation in muscle in response to diffusible bone matrix-derived morphogen. Arch Pathol Lab Med 1978, 102:312-316.

12. Ho SSW, Stern PJ, Bruno LP: Pharmacological inhibition of prostaglandin $\mathrm{E}-2$ in bone and its effect on pathological new bone formation in a rat brain model. Trans Orthop Res Soc 1988, 13:536.

13. Chalmers J, Gray DH, Rush J: Observations on the induction of bone in sofe tissues. J Bone Joint Surg (Br) 1975, 57:36-45.

14. Botolin S, Mauffrey C, Hammerberg EM, Hak DJ, Stahel PF: Heterotopic ossification in the reaming tract of a percutaneous antegrade femoral nail: a case report. J Med Case Rep 2013, 7:90.

15. Schipani E, Ryan HE, Didrickson S, Kobayashi T, Knight M, Johnson RS: Hypoxia in cartilage: HIF-1alpha is essential for chondrocyte growth arrest and survival. Genes Dev 2001, 15:2865-2876.

16. Garland DE, Blum CE, Waters RL: Periarticular heterotopic ossification in head-injured adult. Incidence and location. J Bone Joint Surg Am 1980, 62:1143-1146.

17. Mielants $\mathrm{H}$, Vanhove E, de Neels J, Veys E: Clinical surgery of and pathogenic approach to para-articular ossificans in long-term coma. Acta Orthop Scand 1975, 46:190-198.

18. Tay SS, Lim PA: Acquired heterotopic ossification following encephalitis and intractable seizures. Ann Acad Med Singapour 2008, 37:809-810.

19. Subbarao JV, Garrison SJ: Heterotopic ossification: diagnosis and management, current concepts and controversies. J Spinal Cord Med 1999, 22:273-283.

20. Schurch B, Capaul M, Vallotton MB, Rossier AB: Prostaglandin E2 measurements: their value in the early diagnosis of heterotopic ossification in spinal cord injury patients. Arch Phys Med Rehabil 1997, 78:687-691

21. Sawyer JR, Myers MA, Rosier RN, Puzas JE: Heterotopic ossification: clinical and cellular aspects. Calcif Tissue Int 1991, 49:208-215.

22. Garland DE: Early excision of heterotopic ossification about the elbow followed by radiation therapy. J Bone Joint Surg Am 1998, 80:453-454.

23. Peterson JR, Okagbare PI, De La Rosa S, Cilwa KE, Perosky JE, Eboda ON, Donneys A, Su GL, Buchman SR, Cederna PS, Wang SC, Kozloff KM, Morris 
$M D$, Levi B: Early detection of burn induced heterotopic ossification using transcutaneous Raman spectroscopy. Bone 2013, 54:28-34.

24. Banovac K, Williams JM, Patrick LD, Haniff YM: Prevention of heterotopic ossification spinal injury with indomethacin. Spinal Cord 2001, 39:370-374.

25. Johnson EE, Kay RM, Dorey FJ: Heterotopic ossification prophylaxis

following operative treatment for acetabular fracture. Clin Orthop Relat Res 1994, 305:88-95.

26. Coventry MB, Scanlno PW: The use of radiation to discourage ectopic bone, a nine-year study in surgy about the hip. $J$ Bone Joint Surg Am 1981, 63:201-208.

27. Garland DE, Hanscom DA, Keenan MA, Smith C, Moore T: Resection of heterotopic ossification in the adult with head trauma. J Bone Joint Surg Am 1985, 67:1261-1269.

28. Pittenger DE: Heterotopic ossification. Orthop Rev 1991, 20:33-39.

29. Garland DE: A clinical perspective on common forms of acquired heterotopic ossification. Clin Orthop Relat Res 1991, 263:13-29.

30. Saito N, Horiuchi H, Takahashi H: Heterotopic ossification in the knee following encephalitis: a case report with a 10-year follow-up. Knee 2004, 11:63-65.

31. Devnani AS: Management of heterotopic ossification affecting both hips and knees. Singapore Med J 2008, 49:501-504.

doi:10.1186/1471-2482-14-74

Cite this article as: Zhang et al:: Acquired heterotopic ossification in hips and knees following encephalitis: case report and literature review. BMC Surgery 2014 14:74.

\section{Submit your next manuscript to BioMed Central and take full advantage of:}

- Convenient online submission

- Thorough peer review

- No space constraints or color figure charges

- Immediate publication on acceptance

- Inclusion in PubMed, CAS, Scopus and Google Scholar

- Research which is freely available for redistribution 